\title{
Persistent Cue-Evoked Activity of Accumbens Neurons after Prolonged Abstinence from Self-Administered Cocaine
}

\author{
Udi E. Ghitza, Anthony T. Fabbricatore, Volodymyr Prokopenko, Anthony P. Pawlak, and Mark 0. West \\ Department of Psychology, Rutgers University, Piscataway, New Jersey 08854
}

\begin{abstract}
Persistent neural processing of information regarding drug-predictive environmental stimuli may be involved in motivating drug abusers to engage in drug seeking after abstinence. The addictive effects of various drugs depend on the mesocorticolimbic dopamine system innervating the nucleus accumbens. We used single-unit recording in rats to test whether accumbens neurons exhibit responses to a discriminative stimulus $\left(S^{D}\right)$ tone previously paired with cocaine availability during cocaine self-administration. Presentation of the tone after 3- 4 weeks of abstinence resulted in a cue-induced relapse of drug seeking under extinction conditions. Accumbens neurons did not exhibit tone-evoked activity before cocaine self-administration training but exhibited significant $S^{\mathrm{D}}$ tone-evoked activity during extinction. Under extinction conditions, shell neurons exhibited significantly greater activity evoked by the $S^{\mathrm{D}}$ tone than that evoked by a neutral tone (i.e., never paired with reinforcement). In contrast, core neurons responded indiscriminately to presentations of the $S^{D}$ tone or the neutral tone. Accumbens shell neurons exhibited significantly greater $S^{\mathrm{D}}$ tone-evoked activity than did accumbens core neurons. Although the onset of $S^{\mathrm{D}}$ tone-evoked activity occurred well before the earliest movements commenced $(150 \mathrm{msec})$, this activity often persisted beyond the onset of tone-evoked movements. These results indicate that accumbens shell neurons exhibit persistent processing of information regarding reward-related stimuli after prolonged drug abstinence. Moreover, the accumbens shell appears to be involved in discriminating the motivational value of reward-related associative stimuli, whereas the accumbens core does not.
\end{abstract}

Key words: addiction; self-administration; drug; cocaine; psychomotor stimulant; nucleus accumbens; neuron; electrophysiology; reinforcement; reward; incentive motivation; relapse; cue; conditioning

\section{Introduction}

Exposure to environmental stimuli paired with past drug use may increase the risk for relapse in drug abusers despite prolonged abstinence (Childress et al., 1992), posing a major obstacle in treating drug dependence. Persistent neural processing of information regarding drug-related cues may be involved in motivating drug abusers to engage in drug seeking. However, there is little available data regarding neural substrates responsible for processing information about drug-paired cues after abstinence.

The habit-forming effects of various drugs depend on the mesocorticolimbic dopamine system (Wise and Bozarth, 1987; Koob and Bloom, 1988; Saal et al., 2003) innervating the nucleus accumbens (NAcc) (Roberts et al., 1980; Pettit et al., 1984; Zito et al., 1985; Wise and Rompre, 1989). The NAcc is innervated by limbic regions, such as the amygdala, prefrontal cortex, and hippocampus, and projects via ventral pallidum to thalamic, brainstem somatomotor, and autonomic effector sites. Therefore, the NAcc has been described as a neural substrate for goal-directed behavior (Nauta et al., 1978; Mogenson et al., 1980). Excitotoxic lesions of the NAcc abolish Pavlovian to instrumental transfer (PIT) (Corbit et al., 2001), which may be a mechanism through

Received April 9, 2003; revised June 11, 2003; accepted June 12, 2003.

This work was supported by National Institute on Drug Abuse Grant DA 06886. We thank Linda King for conducting histological procedures, and Esther Prado, Meghana Sreevatsava, and Bethany Lussier for technical assistance.

Correspondence should be addressed to Dr. Mark 0. West, Department of Psychology, Rutgers University, 152 Freylinghuysen Road, Piscataway, NJ 08854. E-mail: markwest@rci.rutgers.edu.

Copyright $\odot 2003$ Society for Neuroscience $\quad$ 0270-6474/03/237239-07\$15.00/0 which emotionally significant stimuli paired with past drug use influence drug seeking despite prolonged abstinence.

The present study investigated the role of NAcc neurons in processing information regarding drug-associated environmental stimuli after prolonged abstinence. Because behavioral evidence indicates that the NAcc core and shell subserve different functions (Parkinson et al., 1999; Corbit et al., 2001), differences between core and shell neural activity correlated with drugassociated stimuli were assessed. The following hypotheses were tested: (1) a tone that served as a discriminative stimulus $\left(\mathrm{S}^{\mathrm{D}}\right)$ signaling drug availability will, after prolonged abstinence, trigger relapse of drug seeking when presented under extinction conditions; (2) during this cue-controlled relapse of drug seeking, NAcc neurons will exhibit responses to the tone, (3) core and shell neurons will respond differently to the tone; and (4) NAcc neurons that exhibit responses to the drug-related tone will not respond to a tone of different frequency that has not been associated with any incentive. This last hypothesis tests whether NAcc neurons respond selectively to motivationally significant stimuli.

Rats were trained for 2 weeks in a tone discrimination paradigm. Individual lever presses that occurred during tone presentation produced an intravenous infusion of cocaine and terminated the tone. After 3-4 weeks of abstinence, NAcc single-unit activity was recorded (1) during cue-induced reinstatement of drug seeking upon reexposure to the tone under extinction conditions and (2) during a session when a tone that had never been paired with reward was presented. Tone-evoked neural activity 
was assessed only during the period between tone onset and movement onset to allow the purest assessment of incentive processing.

\section{Materials and Methods}

Surgery. In 16 male (280-350 gm) Long-Evans rats (Charles River, Raleigh, NC), a catheter was surgically implanted in the jugular vein. An array of 16 microwires (diameter of each uninsulated wire tip, $50 \mu \mathrm{m}$ ) (California Fine Wire, Grove City, CA) was arranged in two parallel rows, which were $\sim 2.6 \mathrm{~mm}$ in length and separated from one another by $0.45-0.55 \mathrm{~mm}$ (wire center to wire center). This array was implanted in the NAcc according to the atlas of Paxinos and Watson (1997). Surgery, coordinates, and procedures used for postoperative maintenance were described previously (Peoples and West, 1996).

Electrophysiological recording sessions preceding first cocaine selfadministration session. Before the first cocaine self-administration session, one to two recording sessions were conducted in which audible tones $(3.5 \mathrm{kHz}, 70 \mathrm{~dB}$; or $750 \mathrm{~Hz}, 70 \mathrm{~dB}$; counterbalanced across animals) were presented to subjects to test whether tone-evoked responses of NAcc neurons were present before conditioning commenced. Tones were presented over a $6-8 \mathrm{hr}$ period and were spaced 3-6 min apart, similar to subsequent cocaine self-administration sessions.

The procedures used for electrophysiological recording and waveform discrimination were described previously (Peoples and West, 1996; Peoples et al., 1999).

Cocaine self-administration sessions. Before the beginning of each selfadministration session, a nonretractable response lever was mounted on a side wall of the chamber. Each lever press in the presence of an audible tone $(3.5 \mathrm{kHz}, 70 \mathrm{~dB}$; or $750 \mathrm{~Hz}, 70 \mathrm{~dB}$; counterbalanced across animals) produced an intravenous infusion of cocaine $(0.35 \mathrm{mg} / \mathrm{kg}$ infusion $)$, terminated the tone, and started an intertone interval (3-6 min). If lever pressing did not occur during a $2 \mathrm{~min}$ tone presentation period, the tone was terminated, and an intertone interval began. Each cocaine selfadministration session lasted between 70 and 80 trials ( $6-8 \mathrm{hr}$ ). Two to 4 weeks of self-administration training preceded the onset of a 3-4 week period of drug abstinence in which the subjects were withdrawn from self-administration. For two rats, 1 week of self-administration training preceded the onset of a 3-4 week period of abstinence. For two other rats, 2 weeks of abstinence followed the 2-4 weeks of cocaine selfadministration training. These four rats were included in the study, because behavioral analyses indicated that they exhibited typical tone discrimination behavior during extinction consistent with that of the other experimental subjects.

Extinction sessions. After a 3-4 week period of drug abstinence, an extinction session was conducted in which a saline infusion replaced the cocaine infusion when the animal lever pressed in the presence of the tone. If no press occurred during the tone, the tone was terminated after $30 \mathrm{sec}$, initiating the same intertone interval as used during the selfadministration training sessions. The tone was presented over a $6-8 \mathrm{hr}$ period. This extinction session assessed whether the tone (an $S^{D}$ predictive of drug availability) triggered cue-controlled relapse of drug seeking after prolonged abstinence from drug taking. The principal measure of tone discrimination was the difference between the number of lever presses in the presence versus the absence of the tone during this extinction session. Specifically, in the first hour, the lever was installed, but no tones were presented to permit assessment of baseline rate of lever pressing. After $1 \mathrm{hr}$, presentations of the tone commenced. Up to three extinction sessions were conducted in each animal to completely extinguish responding.

Neutral tone session. After extinction, a neutral tone session was conducted. In the neutral tone session, a tone that had never been paired with reinforcement (neutral tone) $(750 \mathrm{~Hz}, 70 \mathrm{~dB}$; or $3.5 \mathrm{kHz}, 70 \mathrm{~dB}$; counterbalanced across animals) was presented to test whether NAcc neural responses differentiate between auditory stimuli depending on their motivational value. The timing of tone presentation was the same as that during extinction sessions.

Histology. After neural recording sessions, animals were injected with a lethal dose of sodium pentobarbital. Anodal current ( $50 \mu \mathrm{A}$ for $4 \mathrm{sec}$ ) was passed through each microwire. Animals were perfused with formalinsaline. The brain was removed and fixed in a solution of formalin and sucrose. Coronal sections $(50 \mu \mathrm{m})$ through the NAcc were mounted on slides and incubated in a solution of $5 \%$ potassium ferricyanide and a $10 \% \mathrm{HCl}$ to stain the iron deposits left by the recording tip (Green, 1958). The tissue was counterstained with $0.2 \%$ solution of neutral red and coverslipped. The location of each recorded neuron was plotted on the coronal plate (Paxinos and Watson, 1997) that most closely corresponded to its anterior-posterior position. Neurons were assigned to the core or shell as follows: (1) lesion centers within $150 \mu \mathrm{m}$ of any border were characterized as border neurons, (2) those neurons that bordered extra-accumbal structures were eliminated, and (3) border neurons between the core and shell were eliminated. NAcc shell and core subregions were defined according to the classification used by Jongen-Relo et al. (1994) and Reidel et al. (2002) in which the shell and core subsume the medial and lateral regions of the rostral pole, respectively, in a similar manner as in the remainder of the NAcc.

Behavioral analysis of cue-controlled relapse of drug seeking after prolonged abstinence from drug taking. The principal behavioral index that was used to evaluate the ability of the $S^{\mathrm{D}}$ tone to induce drug seeking was the comparison of the number of drug-seeking responses (lever presses) during the phase of the extinction session in which the $S^{D}$ tone was presented (termed P2) versus the number of lever presses during the preceding phase of the extinction session without the $S^{D}$ tone (termed P1). A unidirectional Wilcoxon matched-pairs signed-ranks test with an $\alpha$ level of 0.05 (Siegel, 1956) was used across subjects to compare the number of lever presses during P2 versus P1 (data were not normally distributed). The matched pairs were the number of lever presses during the first hour of extinction (when the lever was present, but no tones were presented) versus the number of lever presses during the second hour of the extinction session, which was the first hour in which the $S^{D}$ tone was presented.

Construction of perievent time histograms. Precise timing of firing in response to tone presentation was determined by constructing rasters and perievent time histograms that illustrate neuronal discharges within milliseconds before and after tone onset. To operationally define firing that is evoked by tone onset as a response occurring before movement onset, frame-by-frame analyses of computer-synchronized videotapes (30 frames/sec) were used to identify the onset of each tone-evoked movement. The minimal reaction time for initiation of movement across animals was $150 \mathrm{msec}$ after tone onset. An episode of tone-evoked movement was defined as a break from ongoing patterns of movement (e.g., focused stereotypy or grooming) to a different pattern of movement initiated after tone onset. Tone-evoked movements typically consisted of distinct head movements with velocity and magnitude several times higher than ongoing movements that preceded tone onset. This analysis was conducted for extinction experiments in which animals exhibited tone-evoked movements.

Analysis of tone-evoked activity exhibited by NAcc core and shell neurons. The magnitude of tone-evoked changes in firing that occurred before movement onset was standardized and calculated for all of the NAcc neurons in the following manner. A ratio, $B /(A+B)$, was calculated for every neuron, with $A$ equal to the firing rate of the neuron during the 150 msec period before tone onset and $B$ equal to the firing rate of the neuron during the $150 \mathrm{msec}$ period after tone onset. The $150 \mathrm{msec}$ period preceded any tone-evoked movements. A two-way ANOVA with an $\alpha$ level of 0.05 was conducted to evaluate differences in the magnitude of toneevoked activity between neurons in NAcc subregions across extinction and the neutral tone session. To conduct the two-way ANOVA, an exponential monotonic transformation of data was used to transform the non-normal distribution into a normal distribution (Ferketich and Verran, 1994). To evaluate group differences, planned comparisons using a bidirectional Mann-Whitney $U$ test with an $\alpha$ level of 0.01 to reduce type I error (Siegel, 1956) were conducted to assess (1) differences in the magnitude of tone-evoked activity between core and shell neurons during extinction, (2) differences between core and shell neurons in magnitude of activity evoked by the neutral tone, (3) differences in the magnitude of tone-evoked activity during extinction versus during the neutral tone session, and (4) differences in magnitude of tone-evoked activity of 
NAcc neurons before conditioning versus during extinction. To calculate effect size estimates for the nonparametric tests conducted, the raw data were transformed into rank values for which the partial $\eta^{2}$ statistic was calculated as described by Morse (1999).

Analyses of onset latency and duration of tone-evoked activity. By definition, it was not possible to perform this analysis on neurons that exhibited little or no response to the tone. Therefore, analysis was performed on all of the neurons that exhibited at least a twofold change in activity during the $150 \mathrm{msec}$ after tone onset. The onset of tone-evoked activity was defined as the first of four consecutive $20 \mathrm{msec}$ bins in the 150 msec window after tone onset exhibiting at least a twofold change in firing rate relative to the mean firing rate during the $150 \mathrm{msec}$ period preceding tone onset. Second, the offset of tone-evoked activity was defined as the first of four consecutive $20 \mathrm{msec}$ bins (subsequent to the onset of tone-evoked activity) exhibiting less than a twofold change in firing rate relative to the mean firing rate during the $150 \mathrm{msec}$ period preceding tone onset. Duration of tone-evoked activity was defined as the difference between the onset and the offset of tone-evoked activity.

\section{Results}

\section{Behavior}

On the final training session, the mean percentage of tone presentations on which rats lever pressed was $97 \pm 1.6 \%$. By the end of tone discrimination training, all of the rats self-administered levels of cocaine that remained stable throughout the session at $\sim 2-3 \mathrm{mg} / \mathrm{kg}$ calculated blood level of drug (Peoples et al., 1997, 1999). Rats also lever pressed in the absence of the tone, suggesting that self-administration behavior was also influenced by interoceptive cues related to the blood level of the drug (Yokel and Pickens, 1974).

A distinct index of tone discrimination is whether the tone acts as a conditioned incentive during an extinction session. During the first hour of extinction (when the lever was present, but the $S^{\mathrm{D}}$ tone was not presented), animals made $3 \pm 1$ lever presses (mean \pm SEM). In contrast, during the second hour of extinction (when the lever was present, and the $S^{\mathrm{D}}$ tone was presented), animals made $39 \pm 11$ lever presses (mean \pm SEM). A Wilcoxon matched-pairs signed-ranks test revealed that animals engaged in more episodes of drug seeking (lever presses) in extinction sessions during the hour when the $S^{\mathrm{D}}$ tone was presented than during the hour when the tone was never presented $(z=-3.297$; $p<$ $0.01)$. Analysis of effect size revealed a partial $\eta^{2}$ value of 0.45 , which is more than three times the value $(0.14)$ considered to be a large effect size (Cohen, 1988). These data demonstrate that, after 2 weeks of daily cocaine self-administration training and 3-4 weeks of abstinence, the $S^{\mathrm{D}}$ tone had acquired conditioned incentive properties sufficiently potent to trigger relapse of drug seeking in the absence of any primary reinforcement.

\section{Differences in magnitude of tone-evoked activity across sessions and NAcc regions}

Tone-evoked responses of NAcc neurons $(n=70)$ during extinction were significantly greater than before conditioning $(z=$ -4.638; $p<0.001$; Mann-Whitney $U$ test) (Figs. 1 and 2). The partial $\eta^{2}$ value $(0.231)$ indicated a large effect size.

A two-way ANOVA revealed that there was a significant twoway interaction between extinction session versus neutral tone session, and NAcc shell neurons $(n=34)$ versus NAcc core neurons $(n=36)\left(F_{(3,96)}=6.622 ; p<0.05\right)$. In extinction, during presentation of the tone that had been the $S^{\mathrm{D}}$, NAcc shell neurons exhibited greater tone-evoked activity than did core neurons $(z=$ -5.319; $p<0.001$; Mann-Whitney $U$ test) (Fig. 3). The partial $\eta^{2}$ value (0.412) indicated a large effect size. Conversely, during the neutral tone session, core neurons exhibited greater activity

$\frac{S^{D} \text { tone }}{\text { before }} \begin{gathered}\text { during } \\ \text { conditioning } \\ \text { extinction }\end{gathered}$

Neutral tone

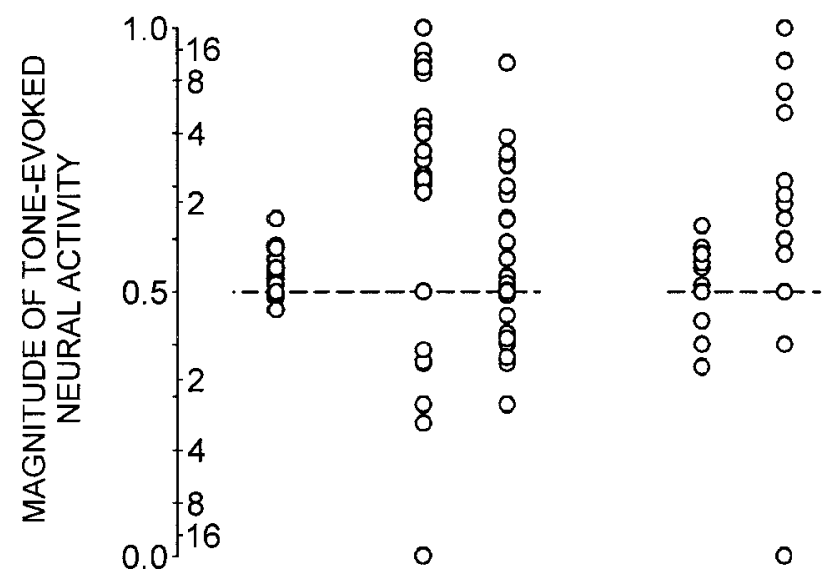

\section{$\begin{array}{lllll}1 & 1 & 1 & 1 & 1\end{array}$ \\ ALL SHELL CORE SHELL CORE NEURONS}

Figure 1. Magnitude of tone-evoked activity as a function of session type and NAcc region. Magnitude of tone-evoked activity of each neuron is expressed as $B /(A+B)$ value (left side of $y$-scale), where $B$ is the firing rate $(\mathrm{Hz})$ in the $150 \mathrm{msec}$ after tone onset, and $A$ is the firing rate (baseline) in the $150 \mathrm{msec}$ preceding tone onset. Each dot represents one neuron. Right side of $y$-scale indicates twofold, fourfold, etc., increases above, or decreases below, baseline value. Dashed horizontal line at 0.5 value indicates no change from control value. Left, Magnitude of $S^{D}$ tone-evoked activity was significantly greater during extinction than before conditioning $(p<0.001)$. During extinction, shell neurons exhibited significantly greater $S^{D}$ tone-evoked activity than did core neurons $(p<0.001)$. Right, Core neurons exhibited significantly greater activity evoked by the neutral tone than did shell neurons $(p<0.005)$. Left, Right, Shell neurons exhibited significantly greater $S^{D}$ tone-evoked activity than neutral tone-evoked activity $(p<0.001)$. In contrast, core neurons exhibited a nonsignificant trend toward greater activity evoked by the neutral tone than by the $S^{\mathrm{D}}$ tone $(p=0.013)$.

evoked by the neutral tone than did shell neurons $(z=-3.226$; $p<0.005$; Mann-Whitney $U$ test) (Figs. 1 and 3). The partial $\eta^{2}$ value (0.364) indicated a large effect size. Shell neurons exhibited significantly greater $S^{\mathrm{D}}$ tone-evoked activity than neutral toneevoked activity $(z=-5.076 ; p<0.001$; Mann-Whitney $U$ test $)$. In contrast, core neurons did not. In fact, core neurons exhibited a nonsignificant trend toward greater activity evoked by the neutral tone than by the $S^{\mathrm{D}}$ tone $(z=-2.491 ; p=0.013$; MannWhitney $U$ test).

Response onset latencies and duration of tone-evoked activity Of the NAcc shell and NAcc core neurons recorded during extinction, 37 neurons (53\%) exhibited at least a twofold, toneevoked change in firing within $150 \mathrm{msec}$ after tone onset, relative to baseline firing during the $150 \mathrm{msec}$ time period preceding tone onset. Of these 37 neurons, 29 (78\%) were shell neurons and 8 (22\%) were core neurons. The rapid response onset latencies of these neurons (mean response onset latency of $54 \mathrm{msec}$ ) indicate that these tone-evoked changes in firing are not related to movement, because across animals, the minimal reaction time from tone onset to tone-evoked movement onset was $150 \mathrm{msec}$. The median time of movement onset across animals was 300 msec. NAcc neurons displayed diverse forms and durations of the toneevoked change in firing (Fig. 4). Of the NAcc neurons exhibiting $S^{\mathrm{D}}$ tone-evoked activity, $76 \%$ were excited and $24 \%$ were inhib- 


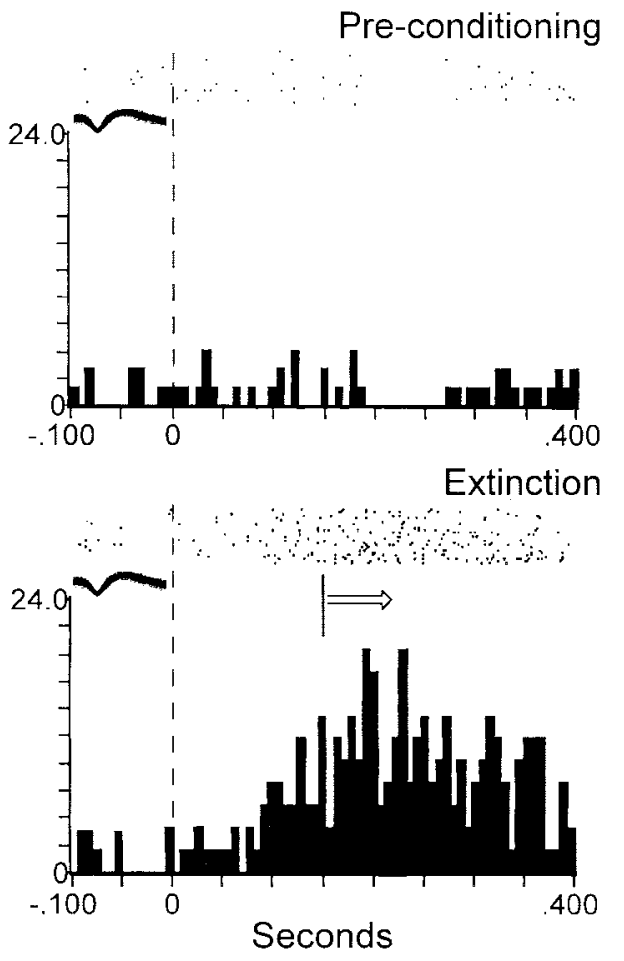

Figure 2. Dependence of tone-evoked activity of shell neuron on type of experimental session. Top, Absence of tone-evoked activity of a shell neuron before conditioning. Bottom, Example of $S^{D}$ tone-evoked activity of the same neuron [met all of the criteria of Peoples et al. (1999)] during extinction after prolonged abstinence. The ordinate of each histogram displays average firing rate (impulses per second); time 0 on the abscissa (also denoted by vertical dashed line) indicates tone onset. Arrow indicates that tone-evoked movements began at various times subsequent to the minimal reaction time ( $150 \mathrm{msec}$ ) across animals, denoted by vertical solid line. The median reaction time across animals was $300 \mathrm{msec}$. Arrow is used similarly in Figures 3 and 4. Above each histogram, a raster display shows firing of the neuron on a trial-by-trial basis. Trials are shown chronologically from the bottom row to the top row. All of the axes are labeled similarly in Figures $2-4$. The overlaid waveforms in Figures $2-4$ represent the neurons whose activity is depicted in the histograms.

ited by the tone. Although the tone-evoked change in firing of these neurons commenced before the onset of tone-evoked movements, the change persisted beyond the onset of tone-evoked movements for $86 \%$ of the neurons. The median duration of the toneevoked activity exhibited by these neurons was $1.1 \mathrm{sec}$.

\section{Discussion}

A central issue in drug addiction research is to elucidate neural substrates of drug relapse after prolonged abstinence. Contemporary theories of drug addiction have focused attention on identifying neuroadaptations in the mesocorticolimbic dopamine system innervating the NAcc (Robinson and Berridge, 1993, 2000; Di Chiara et al., 1999). Repeated actions of abused drugs alter this system, which normally contributes to goal-directed behavior, such that excessive incentive-motivation to selfadminister drug is generated upon exposure to the drug or to environmental stimuli associated with drug taking. The aim of the present study was to investigate whether NAcc neurons exhibit conditioned responses to drug-associated environmental stimuli after prolonged abstinence.

\section{Advantages of present experimental design}

Previous studies have identified rapid-phasic firing patterns of NAcc neurons that exhibit changes time locked within seconds of the cocaine-reinforced instrumental response (Carelli et al.,

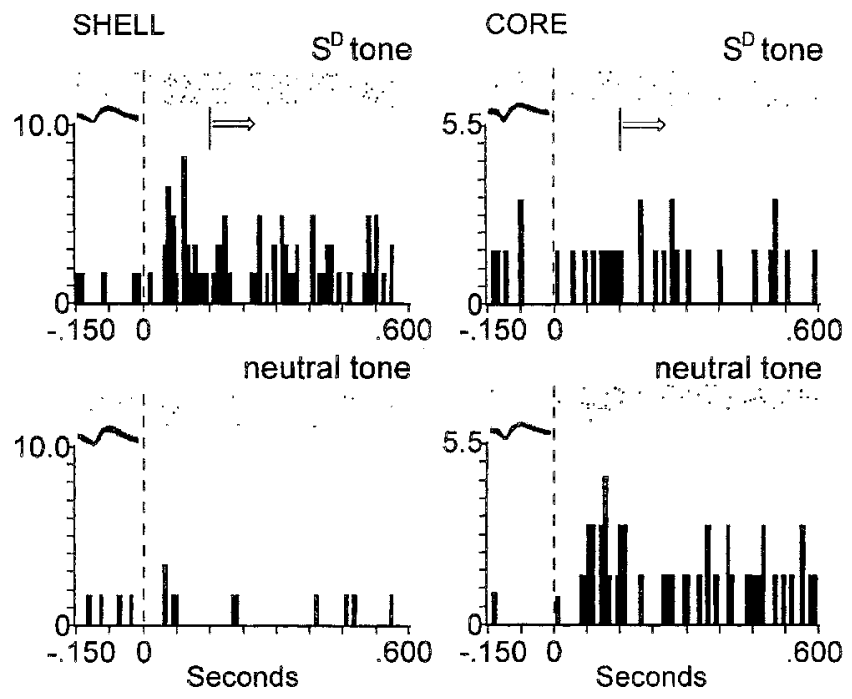

Figure 3. During extinction, shell neurons exhibit selective $S^{D}$ tone-evoked activity, whereas core neurons do not. Left, Top, Example of $S^{D}$ tone-evoked activity of a shell neuron. Bottom, In same shell neuron, lack of activity evoked by the neutral tone. Right, Top, Lack of $S^{D}$ tone-evoked activity of core neuron. Bottom, In same core neuron, activity evoked by the neutral tone. See Figure 2 legend for description of axes and symbols.

1993; Chang et al., 1994; Carelli and Deadwyler, 1996; Peoples et al., 1997). However, these firing patterns coincided with numerous events: instrumental response, tone on, pump activation, interoceptive signals regarding the infusion into the cardiovascular system, and others. Because of these coinciding factors, the precise relevance of these firing patterns to motivation could not be evaluated. The present design tested firing in the absence of drug or movement, and eliminated all but one salient event: the $\mathrm{S}^{\mathrm{D}}$ tone. Moreover, in the present study, instrumental responding in extinction was not influenced by interoceptive drug cues that often affect rate of instrumental responding and other behavioral measures during drug self-administration (Yokel and Pickens, 1974). Interoceptive drug cues also have been shown to affect phasic firing patterns of NAcc neurons that are correlated with the timing of cocaine seeking during cocaine selfadministration (Peoples and West, 1996; Carelli and Deadwyler, 1997; Nicola and Deadwyler, 2000). However, such factors could not have influenced the present tone-evoked firing. Assessing the excitatory influence of conditioned incentive cues on instrumental responding during extinction conditions is consistent with methodology used previously (Wyvell and Berridge, 2000; Corbit et al., 2001).

\section{Principal findings}

A tone that had served as the $S^{\mathrm{D}}$ predictive of drug reward induced relapse of drug seeking during the extinction session, as evidenced by increased episodes of drug seeking in the presence of the tone compared with the absence of the tone. During the same extinction session, NAcc shell neurons exhibited more robust $S^{\mathrm{D}}$ tone-evoked activity than NAcc core neurons. This toneevoked activity was not present before the tone was paired with drug availability and thus represents a conditioned response to the tone. Moreover, shell neurons exhibited little or no response to a neutral tone that had never been paired with drug availability. In contrast, core neurons responded indiscriminately to presentations of the $\mathrm{S}^{\mathrm{D}}$ tone or the neutral tone. Thus, in contrast to core neurons, shell neurons may be involved in selectively responding to reward-related associative stimuli. This is the first 
A

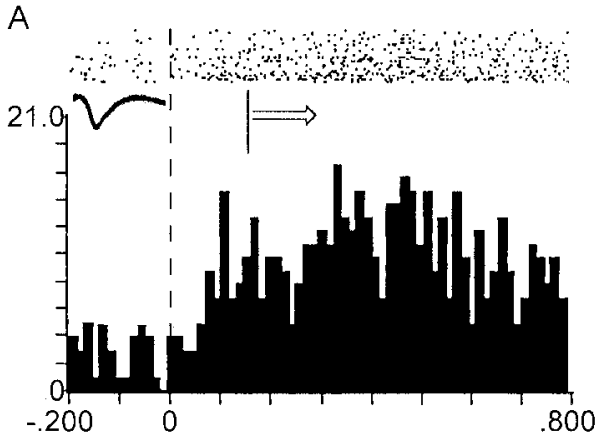

$\mathrm{B}$

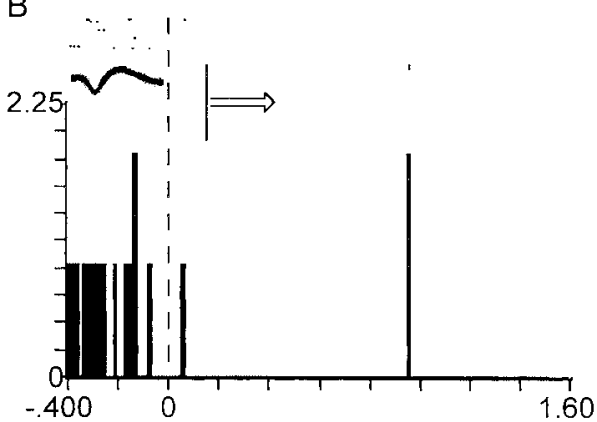

C

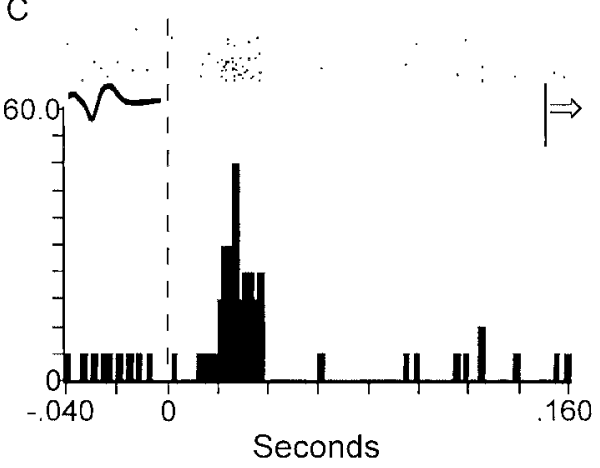

Figure 4. Examples of diverse forms and durations of the tone-evoked change in firing between different shell neurons. A, An example of a shell neuron that exhibited a tone-evoked increase in firing that was initiated before movement and persisted beyond the onset of toneevoked movements. This tone-evoked change in firing was the most commonly observed response type. Of all of the accumbens (core and shell) neurons, 33\% exhibited this response type. $B$, An example of a shell neuron that exhibited a tone-evoked decrease in firing that was initiated before movement and persisted beyond the onset of tone-evoked movements. Of all of the accumbens neurons, 13\% exhibited this response type. C, An example of a shell neuron that exhibited a tone-evoked change in firing with a short duration that preceded the onset of tone-evoked movements. Of all of the accumbens neurons, 7\% exhibited this response type. See Figure 2 legend for description of axes and symbols.

study to show that NAcc shell neurons are persistently and selectively involved in processing information related to drugassociated environmental stimuli after prolonged abstinence. Onset of these tone-evoked firing patterns occurred well before the earliest movements commenced, consistent with evidence suggesting that the NAcc participates in initiating appetitive behavior in response to conditioned incentives (Corbit et al., 2001).

\section{Different roles of the NAcc core and shell in addiction}

Behavioral evidence indicates that the NAcc core and shell subserve different functions (Parkinson et al., 1999; Corbit et al., 2001). Various drugs of abuse, including cocaine, PCP, and amphetamine, are self-administered into the shell region but not into the core region of the NAcc (Carlezon and Wise, 1996;
McKinzie et al., 1999; Chevrette et al., 2002; Rodd-Henricks et al., 2002). Converging evidence indicates that a common pathway of addiction is the mesocorticolimbic dopaminergic system innervating the NAcc shell region, which is necessary for the reinforcing effects of various drugs of abuse (for review, see Di Chiara, 2002).

In addition to functional differences between the NAcc core and shell regions with respect to the incentive-motivational effects of drugs of abuse, recent evidence indicates that the NAcc shell region may be necessary for Pavlovian-instrumental transfer. Corbit et al. (2001) found that excitotoxic lesions of the shell, but not the core, abolish PIT. Moreover, amphetamine infused directly into the shell potentiates PIT (Wyvell and Berridge, 2000 ), indicating that the ability of emotionally significant conditioned stimuli to facilitate goal-directed behavior is enhanced by increased dopamine transmission in the NAcc shell. This enhanced ability of reward-related cues to influence goal-directed behavior may be relevant to drug addiction, because drug-related environmental stimuli are readily associated with the rewarding effects of various drugs of abuse, and these cues commonly elicit drug seeking and drug taking. Moreover, drug reward-related cues may induce intense craving for drugs in addicts even after extended drug withdrawal (Childress et al., 1992). Together with findings that excitotoxic lesions of the NAcc shell abolish PIT, the data in the present study suggest the following roles for the NAcc shell in cue-controlled relapse of drug seeking after prolonged abstinence: (1) the NAcc shell may be a structure through which neural processing of environmental stimuli previously paired with reward may mobilize goal-directed actions instrumental for obtaining incentives after prolonged periods of abstinence; and (2) the NAcc shell may be involved in discriminating the motivational value of associative cues and in activating instrumental actions in response to these cues. In contrast, the NAcc core does not appear to discriminate the motivational value of rewardrelated associative cues.

The processing of the affective attributes of conditioned incentive cues by the shell under extinction conditions in the present study is not likely a function of unlearning the original association between tone and drug during extinction. Considerable behavioral evidence indicates that conditioned responses are quite resistant to loss with passage of time (for review, see Myers and Davis, 2002). For instance, the expression of a conditioned response recurs after extinction (termed "spontaneous recovery"). Moreover, conditioned responses often reappear if the animal is tested in a context different from that in which the extinction took place (termed "renewal") (Bouton and Ricker, 1994) (for review, see Myers and Davis, 2002). These behavioral phenomena suggest a memory of the original association despite the expression of extinction. These behavioral observations support our conclusion that the persistent processing of information regarding the conditioned incentive cue after prolonged abstinence by shell neurons may be related to an involvement of the NAcc shell in mnemonic mechanisms such as reconsolidation of information concerning the motivational significance of conditioned incentive stimuli.

The shell exhibits a pattern of connectivity consistent with that of structures in the extended amygdala and other limbic structures, whereas the core is mostly interconnected with structures characteristic of the circuitry of more dorsal portions of the striatum (Alheid and Heimer, 1988; Heimer et al., 1991; Brog et al., 1993). Recent evidence suggests that components of the extended amygdala are involved in appetitive associative learning 
and drug reinforcement (Robledo and Koob, 1993; Di Chiara et al., 1999; Phillips et al., 2002).

The basolateral amygdala complex is activated during cueinduced drug craving and is involved in cue-induced reinstatement of drug seeking (Meil and See, 1997; Bonson et al., 2002). The amygdala has been implicated in mnemonic processes triggered by retrieval cues (Boujabit et al., 2003). Together with data from the present study, these data suggest that circuitry including the NAcc shell, along with the basolateral amygdala complex, may be involved in reconsolidating the memory of the motivational significance of reward-related associative stimuli whereby the neural representation of the motivational significance of these stimuli mobilizes instrumental behavior.

There is evidence indicating that electrical stimulation of the ventral subiculum of the hippocampal formation triggers relapse to cocaine seeking (Vorel et al., 2001). Limbic projections to the NAcc from the amygdala and hippocampus overlap most completely in the medial (shell) division of the NAcc; in contrast to the NAcc core, the NAcc shell also receives a dense innervation from those limited cortical sites (anterior cingulate cortical and medial prefrontal cortical areas 25 and 32) that receive dense convergent input from the basolateral amygdala complex and hippocampus (Haber et al., 1995; Friedman et al., 2002). The NAcc shell integrates limbic excitatory glutamatergic signals from all of these structures (O'Donnell and Grace, 1995; Mulder et al., 1998). Associative input regarding contextual and discrete drug reward-related cues conveyed by hippocampal, basolateral amygdaloid, ventral tegmental, and prefrontal cortical limbic afferents may converge at the NAcc shell to activate drug seeking.

The persistent $S^{\mathrm{D}}$ tone-evoked firing patterns exhibited by NAcc shell neurons after prolonged abstinence may represent enduring mnemonic processes whereby the motivational significance of drug reward-related stimuli activates instrumental responses necessary to attain drug reinforcement. Such enduring neural representations of drug-related stimuli processed by the NAcc shell can render drug addicts vulnerable to relapse long after initial drug withdrawal.

\section{References}

Alheid GF, Heimer L (1988) New perspectives in basal forebrain organization of special relevance for neuropsychiatric disorders: the striatopallidal, amygdaloid and corticopetal components of substantia innominata. Neuroscience 27:1-39.

Bonson KR, Grant SJ, Contoreggi CS, Links JM, Metcalfe J, Weyl HL, Kurian V, Ernst M, London ED (2002) Neural systems and cue-induced cocaine craving. Neuropsychopharmacology 26:376-386.

Boujabit M, Bontempi B, Destrade C, Gisquet-Verrier P (2003) Exposure to a retrieval cue in rats induces changes in regional brain glucose metabolism in the amygdala and other related brain structures. Neurobiol Learn Mem 79:57-71.

Bouton ME, Ricker ST (1994) Renewal of extinguished responding in a second context. Anim Learn Behav 22:317-324.

Brog JS, Salyapongse A, Deutch AY, Zahm DS (1993) The patterns of afferent innervation of the core and shell in the "accumbens" part of the rat ventral striatum: immunohistochemical detection of retrogradely transported fluoro-gold. J Comp Neurol 338:255-278.

Carelli RM, Deadwyler SA (1996) Dual factors controlling activity of nucleus accumbens cell-firing during cocaine self-administration. Synapse 24:308-311.

Carelli RM, Deadwyler SA (1997) Cellular mechanisms underlying reinforcement-related processing in the nucleus accumbens: electrophysiological studies in behaving animals. Pharmacol Biochem Behav 57:495-504.

Carelli RM, King VC, Hampson RE, Deadwyler SA (1993) Firing patterns of nucleus accumbens neurons during cocaine self-administration in rats. Brain Res 626:14-22.

Carlezon Jr WA, Wise RA (1996) Rewarding actions of phencyclidine and related drugs in nucleus accumbens shell and frontal cortex. J Neurosci 16:3112-3122.

Chang JY, Sawyer SF, Lee RS, Woodward DJ (1994) Electrophysiological and pharmacological evidence for the role of the nucleus accumbens in cocaine self-administration in freely moving rats. J Neurosci 14:1224-1244.

Chevrette J, Stellar JR, Hesse GW, Markou A (2002) Both the shell of the nucleus accumbens and the central nucleus of the amygdala support amphetamine self-administration in rats. Pharmacol Biochem Behav 71:501-507.

Childress AR, McLellan AT, Ehrman R, O’Brien CP (1992) Classically conditioned factors in drug dependence. In: Substance abuse: a comprehensive text book (Lowinson W, Luiz P, Millman RB, Langard JG, eds), pp 56-69. Baltimore: Williams and Wilkins.

Cohen J (1988) Statistical power analysis for the behavioral sciences, Ed 2. Hillsdale, NJ: Lawrence Erlbaum.

Corbit LH, Muir JL, Balleine BW (2001) The role of the nucleus accumbens in instrumental conditioning: evidence of a functional dissociation between accumbens core and shell. J Neurosci 21:3251-3260.

Di Chiara G (2002) Nucleus accumbens shell and core dopamine: differential role in behavior and addiction. Behav Brain Res 137:75-114.

Di Chiara G, Tanda G, Bassareo V, Pontieri F, Acquas E, Fenu S, Cadoni C, Carboni E (1999) Drug addiction as a disorder of associative learning: role of nucleus accumbens shell/extended amygdala dopamine. Ann NY Acad Sci 877:461-485.

Ferketich S, Verran J (1994) An overview of data transformation. Res Nurs Health 17:393-396.

Friedman DP, Aggleton JP, Saunders RC (2002) Comparison of hippocampal, amygdala, and perirhinal projections to the nucleus accumbens: combined anterograde and retrograde tracing study in the macaque brain. J Comp Neurol 450:345-365.

Green JD (1958) A simple microelectrode for recording from the central nervous system. Nature 182:962.

Haber SN, Kunishio K, Mizobuchi M, Lynd-Balta E (1995) The orbital and medial prefrontal circuit through the primate basal ganglia. J Neurosci 15:4851-4867.

Heimer L, Zahm DS, Churchill L, Kalivas PW, Wohltmann C (1991) Specificity in the projection patterns of accumbal core and shell in the rat. Neuroscience 41:89-125.

Jongen-Relo AL, Voorn P, Groenewegen HJ (1994) Immunohistochemical characterization of the shell and core territories of the nucleus accumbens in the rat. Eur J Neurosci 6:1255-1264.

Koob GF, Bloom FE (1988) Cellular and molecular mechanisms of drug dependence. Science 242:715-723.

McKinzie DL, Rodd-Henricks ZA, Dagon CT, Murphy JM, McBride WJ (1999) Cocaine is self-administered into the shell region of the nucleus accumbens in Wistar rats. Ann NY Acad Sci 877:788-791.

Meil WM, See RE (1997) Lesions of the basolateral amygdala abolish the ability of drug associated cues to reinstate responding during withdrawal from self-administered cocaine. Behav Brain Res 87:139-148.

Mogenson GJ, Jones DL, Yim CY (1980) From motivation to action: functional interface between the limbic system and the motor system. Prog Neurobiol 14:69-97.

Morse DT (1999) MINSIZE 2: a computer program for determining effect size and minimum sample size for statistical significance for univariate, multivariate, and nonparametric tests. Educ Psychol Meas 59:518-531.

Mulder AB, Hodenpijl MG, Lopes da Silva FH (1998) Electrophysiology of the hippocampal and amygdaloid projections to the nucleus accumbens of the rat: convergence, segregation and interactions of inputs. J Neurosci 18:5095-5102.

Myers KM, Davis M (2002) Behavioral and neural analysis of extinction. Neuron 36:567-584.

Nauta WJ, Smith GP, Faull RL, Domesick VB (1978) Efferent connections and nigral afferents of the nucleus accumbens septi in the rat. Neuroscience 3:385-401.

Nicola SM, Deadwyler SA (2000) Firing rate of nucleus accumbens neurons is dopamine-dependent and reflects the timing of cocaine-seeking behavior in rats on a progressive ratio schedule of reinforcement. J Neurosci 20:5526-5537.

O’Donnell P, Grace AA (1995) Synaptic interactions among excitatory afferents to nucleus accumbens neurons: hippocampal gating of prefrontal cortical input. J Neurosci 15:3622-3639. 
Parkinson JA, Olmstead MC, Burns LH, Robbins TW, Everitt BJ (1999) Dissociation in effects of lesions of the nucleus accumbens core and shell on appetitive Pavlovian approach behavior and the potentiation of conditioned reinforcement and locomotor activity by D-amphetamine. J Neurosci 19:2401-2411.

Paxinos G, Watson C (1997) The rat brain in stereotaxic coordinates, Ed 3. New York: Academic.

Peoples LL, West MO (1996) Phasic firing of single neurons in the rat nucleus accumbens correlated with the timing of intravenous cocaine selfadministration. J Neurosci 16:3459-3473.

Peoples LL, Uzwiak AJ, Gee F, West MO (1997) Operant behavior during sessions of intravenous cocaine infusion is necessary and sufficient for phasic firing of single nucleus accumbens neurons. Brain Res 757:280-284

Peoples LL, Uzwiak AJ, Gee F, West MO (1999) Tonic firing of rat nucleus accumbens neurons: changes during the first two weeks of daily cocaine self-administration sessions. Brain Res 822:231-236.

Pettit HO, Ettenberg A, Bloom FE, Koob GF (1984) Destruction of dopamine in the nucleus accumbens selectively attenuates cocaine but not heroin self-administration in rats. Psychopharmacology 84:167-173.

Phillips GD, Harmer CJ, Hitchcott PK (2002) Blockade of sensitizationinduced facilitation of appetitive conditioning by post-session intraamygdala nafadotride. Behav Brain Res 134:249-257.

Reidel A, Hartig W, Seeger G, Gartner U, Brauer K, Arendt T (2002) Principles of rat subcortical forebrain organization: a study using histological techniques and multiple fluorescence labeling. J Chem Neuroanat 23:75-104.

Roberts DC, Koob GF, Klonoff P, Fibiger HC (1980) Extinction and recovery of cocaine self-administration following 6-hydroxydopamine lesions of the nucleus accumbens. Pharmacol Biochem Behav 12:781-787.
Robinson TE, Berridge KC (1993) The neural basis of drug craving: an incentive-sensitization theory of addiction. Brain Res Rev 18:247-291.

Robinson TE, Berridge KC (2000) The psychology and neurobiology of addiction: an incentive-sensitization view. Addiction 95:S91-S117.

Robledo P, Koob GF (1993) Two discrete nucleus accumbens projection areas differentially mediate cocaine self-administration in the rat. Behav Brain Res 55:159-166.

Rodd-Henricks ZA, McKinzie DL, Li TK, Murphy JM, McBride WJ (2002) Cocaine is self-administered into the shell but not the core of the nucleus accumbens of Wistar rats. J Pharmacol Exp Ther 303:1216-1226.

Saal D, Dong Y, Bonci A, Malenka RC (2003) Drugs of abuse and stress trigger a common synaptic adaptation in dopamine neurons. Neuron 37:577-582.

Siegel S (1956) Nonparametric statistics for the behavioral sciences. New York: McGraw-Hill.

Vorel SR, Liu X, Hayes RJ, Spector JA, Gardner EL (2001) Relapse to cocaine-seeking after hippocampal $\theta$ burst stimulation. Science 292:1175-1178.

Wise RA, Bozarth MA (1987) A psychomotor stimulant theory of addiction. Psychol Rev 94:469-492.

Wise RA, Rompre PP (1989) Brain dopamine and reward. Annu Rev Psychol 40:191-225.

Wyvell CL, Berridge KC (2000) Intra-accumbens amphetamine increases the conditioned incentive salience of sucrose reward: enhancement of reward "wanting" without enhanced "liking" or response reinforcement. J Neurosci 20:8122-8130.

Yokel AR, Pickens R (1974) Drug level of D- and L-amphetamine during intravenous self-administration. Psychopharmacologia 34:255-264.

Zito KA, Vickers G, Roberts DC (1985) Disruption of cocaine and heroin self-administration following kainic acid lesions of the nucleus accumbens. Pharmacol Biochem Behav 23:1029-1036. 